\title{
The development, fabrication, and material characterization of polypropylene composites reinforced with carbon nanofiber and hydroxyapatite nanorod hybrid fillers
}

\author{
This article was published in the following Dove Press journal: \\ International Journal of Nanomedicine \\ II March 2014 \\ Number of times this article has been viewed
}

\author{
Cheng Zhu Liao ${ }^{1,2}$ \\ Hoi Man Wong ${ }^{3}$ \\ Kelvin Wai Kwok Yeung ${ }^{3}$ \\ Sie Chin Tjong ${ }^{2}$ \\ 'Department of Materials Science \\ and Engineering, South University \\ of Science and Technology of China, \\ Shenzhen, People's Republic of China; \\ ${ }^{2}$ Department of Physics and Materials \\ Science, City University of Hong \\ Kong, ${ }^{3}$ Department of Orthopedics \\ and Traumatology, Li Ka Shing Faculty \\ of Medicine, University of Hong Kong, \\ Hong Kong
}

\begin{abstract}
This study focuses on the design, fabrication, microstructural and property characterization, and biocompatibility evaluation of polypropylene (PP) reinforced with carbon nanofiber (CNF) and hydroxyapatite nanorod (HANR) fillers. The purpose is to develop advanced PP/ CNF-HANR hybrids with good mechanical behavior, thermal stability, and excellent biocompatibility for use as craniofacial implants in orthopedics. Several material-examination techniques, including X-ray diffraction, Fourier-transform infrared spectroscopy, scanning electron microscopy, thermogravimetric analysis, differential scanning calorimetry, tensile tests, and impact measurement are used to characterize the microstructural, mechanical, and thermal properties of the hybrids. Furthermore, osteoblastic cell cultivation and colorimetric assay are also employed for assessing their viability on the composites. The CNF and HANR filler hybridization yields an improvement in Young's modulus, impact strength, thermal stability, and biocompatibility of PP. The PP/2\% CNF-20\% HANR hybrid composite is found to exhibit the highest elastic modulus, tensile strength, thermal stability, and biocompatibility.
\end{abstract}

Keywords: nanocomposite, implant, cellular viability, mechanical behavior

\section{Introduction}

There has been growing interest amongst materials scientists, biomedical engineers, and surgeons in the use of novel biomaterials for the treatment of severe skeletal defects and injuries in recent years. Human bone defects can be caused by trauma, cancer, infection, and congenital abnormality. Autografts taken from the patient's bones and allografts from cadavers are typically used for replacing bone-tissue defects. However, limited supply of autografts and the immunological rejection reaction of allografts are their main drawbacks. In this respect, artificial implants are considered as alternative materials for treating bone disease and trauma.

Metallic materials, such as Fe-based alloy (American Iron and Steel Institute 316 stainless steel), Co-based alloy (60.6 wt $\%$ Co, $31.5 \mathrm{wt} \% \mathrm{Cr}, 6.0 \mathrm{wt} \% \mathrm{Mo}, 1.9 \mathrm{wt} \%$ residuals [Si, Mn and C]; Vitallium $\left.{ }^{\circledR}\right)$, and Ti-based alloy (Ti-6 wt\% Al-4 wt\% V) are typically used as implants in orthopedics. However, metallic materials have many disadvantages for use as bone-replacement implants. Corrosion and wear are major concerns of the long-term performance of metallic prosthesis. Fe-based stainless alloy may suffer pitting corrosion upon exposure to human body fluid containing about $0.9 \% \mathrm{NaCl}{ }^{1}$ This is because chloride ion destroys passive film formed on stainless steel. Moreover, some metallic ions and wear debris released from metallic implants can cause allergy
Correspondence: Sie Chin Tjong Department of Physics and Materials Science, City University of Hong Kong, 83 Tat Chee Avenue, Kowloon, Hong Kong

Tel +85234427702

Fax +85234420538

Email aptjong@cityu.edu.hk 
and infection. ${ }^{2-4}$ Aluminum ions released from the Ti- $6 \mathrm{wt} \%$ Al-4 wt $\% \mathrm{~V}$ alloy can induce Alzheimer's disease, while vanadium ions can modify enzyme activity of the cells. The toxicity of vanadium has driven the development of novel biomaterials for replacing Ti-6Al-4V. Furthermore, Young's modulus of metallic implants is much higher than that of human cortical bone, leading to the so-called stress-shielding effect. Stress shielding is the inhomogeneous transfer of stress between the implant and bone. Young's moduli of 316 stainless steel, CoCrMo alloy, and $\mathrm{Ti}-6 \mathrm{Al}-4 \mathrm{~V}$ alloy are in the ranges of 205-210 GPa, 220-230 GPa, and $115 \mathrm{GPa}$ respectively. They are much higher than Young's modulus of human cortical bone, which ranges from 7 to $30 \mathrm{GPa}^{5}$

Bone tissue is a biocomposite with hydroxyapatite (HA) nanoplatelets dispersed in the collagen matrix. The HA mineral exhibits high hardness and excellent biocompatibility, osteoconductivity, and bioactivity. The designed biocomposites for load-bearing biomedical applications should combine the advantages of both components. ${ }^{6}$ However, synthetic HA collagen composites possess low mechanical strength, and thus are typically used for biodegradable scaffolds in orthopedics. ${ }^{7,8}$ To enhance the mechanical performance of biocomposites, nondegradable polymers, such as high-density polyethylene (HDPE), have been selected as the matrix of HA-reinforced PE composite (HAPEX $\left.{ }^{\mathrm{TM}}\right){ }^{9-11}$ The incorporation of $40 \mathrm{vol} \%$ HA microparticles into HDPE results in a considerable increase in its elastic modulus. However, HAPEX with low tensile strength is mainly used for orbital floor prosthesis, middle ear implant, and maxillofacial surgery. Furthermore, large HA particles with sizes of several micrometers often debond readily from the polymer matrix and fracture into small fragments during mechanical testing. ${ }^{12}$

Recent progress in nanotechnology has allowed the synthesis of nanomaterials with excellent physical and mechanical properties, ${ }^{13}$ as well as biocompatibility. ${ }^{14,15}$ For example, synthetic nanoscale HA strongly promotes the adhesion and proliferation of osteoblasts. ${ }^{16-18}$ Carbon nanotubes (CNTs) with exceptionally high Young's modulus (about $1 \mathrm{TPa}$ ) and excellent electrical conductivity show good biocompatibility towards human cells like osteoblasts, myoblasts, and neurons. ${ }^{19-22}$ In this context, nano-HA and CNTs have been employed as reinforcing fillers for polymers in forming functional composites for biomedical applications. ${ }^{23-32}$ However, CNTs with coiled morphology disperse poorly in the polymeric matrix, especially at higher filler contents. This leads to inferior mechanical performance of the resulting composites. In contrast, carbon nanofibers (CNFs) with a straight feature can better disperse in the polymeric matrix of biocomposites. Other advantages of CNFs include lower production cost and good biocompatibility. In this regard, CNFs have been incorporated into polymers to form functional composites for biomedical applications. ${ }^{33,34} \mathrm{CNFs}$ are generally synthesized by the catalytic decomposition of hydrocarbons on transition metal catalysts, such as Fe, Co, and $\mathrm{Cu}$ nanoparticles, at high temperatures. ${ }^{35-37}$ Straight and helical CNFs can be selectively prepared by properly monitoring the reaction temperature, feed-gas composition, and the shape of metal nanoparticles. In the latter case, Jian et al reported that spherical $\mathrm{Cu}$ nanoparticles favor formation of straight CNFs, while polyhedral or facetted $\mathrm{Cu}$ catalysts yield helical CNFs. ${ }^{37}$

In a previous study, we prepared polypropylene (PP) composites with 5-20 wt\% HA nanorods (HANRs). ${ }^{25}$ The results showed that the addition of $20 \mathrm{wt} \%$ HANRs (6.67 vol\%) to PP improves its mechanical performance and biocompatibility. PP exhibits excellent chemical resistance, durability, dimensional stability, and flexibility. PP exhibits higher fatigue resistance than HDPE, and thus can replace ductile HDPE for biomedical implants experiencing frequent cyclic stress. In this study, we investigated the influence of CNF additions on the structural, thermal, and mechanical behaviors of PP and PP/20 wt $\%$ HANR composites. In the latter case, low CNF loadings $(0.5-2 \mathrm{wt} \%)$ were added to the $\mathrm{PP} / 20 \mathrm{wt} \%$ HANR composite to yield hybrids with higher mechanical performance and biocompatibility. The aim was to develop polymer-composite implants with good biocompatibility for bone-defect repair and replacement, especially for craniofacial applications.

\section{Materials and methods Materials}

PP (Moplen HP500N) was purchased from LyondellBasell Polymers (Saudi Arabia). CNFs of 50-200 nm (diameter) and 0.5-20 $\mu \mathrm{m}$ (length) were obtained from Nanostructured and Amorphous Materials (Houston, TX, USA). HANRs were purchased from Nanjing Emperor Nano Materials (Nanjing, People's Republic of China), with an average width of $20 \mathrm{~nm}$ and length of $120 \mathrm{~nm}$.

\section{Preparation of nanocomposites}

Table 1 list the compositions of $\mathrm{PP} / \mathrm{CNF}$ and $\mathrm{PP} / \mathrm{CNF}-$ HANR composites. The precursor materials of these composites were first melt-extruded in a Brabender (Duisburg, Germany) with blending temperature profiles of $215^{\circ} \mathrm{C}$, $230^{\circ} \mathrm{C}, 230^{\circ} \mathrm{C}, 220^{\circ} \mathrm{C}, 195^{\circ} \mathrm{C}$, and $180^{\circ} \mathrm{C}$ at a rotation speed 
Table I Composition of the composites investigated

\begin{tabular}{llll}
\hline Sample & $\begin{array}{l}\text { PP } \\
\text { (wt\%) }\end{array}$ & $\begin{array}{l}\text { CNF } \\
\text { (wt\%) }\end{array}$ & $\begin{array}{l}\text { HANR } \\
\text { (wt\%) }\end{array}$ \\
\hline PP/0.5\% CNF & 99.5 & 0.5 & 0 \\
PP/I\% CNF & 99 & 1 & 0 \\
PP/2\% CNF & 98 & 2 & 0 \\
PP/20\% HANR & 80 & 0 & 20 \\
PP/0.5\% CNF-20\% HANR & 79.5 & 0.5 & 20 \\
PP/I\% CNF-20\% HANR & 79 & 1 & 20 \\
PP/2\% CNF-20\% HANR & 78 & 2 & 20 \\
\hline
\end{tabular}

Abbreviations: PP, polypropylene; CNF, carbon nanofiber; HANR, hydroxyapatite nanorod.

of $40 \mathrm{rpm}$. The extrudates were pelletized and blended again in the Brabender. The obtained materials were granulized again, dried, and subsequently injection-molded into rectangular plaques. Pure $\mathrm{PP}$ and $\mathrm{PP} / 20 \%$ HANR nanocomposite were also fabricated under the same processing conditions.

\section{Characterization}

X-ray diffraction (XRD) experiments were carried out with a Siemens (Munich, Germany) D500 diffractometer ( $\mathrm{Cu}-\mathrm{K} \alpha$ radiation) operating at $40 \mathrm{kV}$ and $30 \mathrm{~mA}$. Fourier-transform infrared (FTIR) spectra in the range of $400-4,000 \mathrm{~cm}^{-1}$ were recorded with a PerkinElmer (Waltham, MA, USA) spectrometer (16PC). Morphological analysis of the composites was performed in a JEOL (Tokyo, Japan) field-emission scanning electron microscope (FE-SEM; JSM-7100F). The crystallization behavior of $\mathrm{PP} / \mathrm{CNF}$ and $\mathrm{PP} / \mathrm{CNF}-\mathrm{HANR}$ nanocomposites was studied using a differential scanning calorimeter (DSC; model 2910; TA Instruments, New Castle, DE, USA) purged with nitrogen. The specimen was first scanned from room temperature to $200^{\circ} \mathrm{C}$ at $100^{\circ} \mathrm{C} /$ minute, then held for 3 minutes to delete its previous thermal history, followed by cooling at $10^{\circ} \mathrm{C} /$ minute. Thermogravimetric experiments were performed with a TGA Q50 (TA Instruments) in a nitrogen atmosphere from $30^{\circ} \mathrm{C}$ to $550^{\circ} \mathrm{C}$ at $20^{\circ} \mathrm{C} /$ minute. The temperature at $5 \%$ weight loss $\left(T_{5 \%}\right)$ was determined from the weight loss-versus-temperature curves.

Tensile and notched impact specimens were prepared from injection-molded plaques. Tensile tests were performed with an Instron Corporation (Norwood, MA, USA) tester (model 5567) at room temperature at $10 \mathrm{~mm} / \mathrm{minute}$ based on the ASTM D638-08. The Izod impact tests were performed with an impact tester (CEAST model 6545; Instron) according to the ASTM D256-05. Both tensile and impact tests employed six specimens of each composite material, and the average values were determined accordingly.

\section{Cell culture and proliferation}

For the cell-culture experiment, the human osteoblast cell line Saos-2 was grown in Dulbecco's Modified Eagle's Medium (DMEM) with 10\% fetal bovine serum and penicillin/ streptomycin. The samples were sterilized with $70 \%$ ethanol and rinsed with sterile phosphate-buffered saline (PBS). Then, $100 \mu \mathrm{L}$ medium containing $10^{4}$ cells was seeded on sterile samples placed into the wells of a 96-well culture plate. The plate was put into an incubator at $37^{\circ} \mathrm{C}$ under a humidified atmosphere with 5\% $\mathrm{CO}_{2}$ and $95 \%$ air. After cultivation for 48 and 96 hours, respectively, the specimens were rinsed with PBS and treated with $10 \%$ formaldehyde. They were then dehydrated with a series of graded ethanol solutions, followed by critical point drying. The cellular constructs were sputter-coated with gold, and imaged in a scanning electron microscope (SEM).

The cell viability of samples was determined with a 3-(4,5-dimethylthiazol-2-yl)-2,5-diphenyltetrazolium bromide (MTT) assay. Samples placed in a 96-well plate were seeded with $100 \mu \mathrm{L}$ suspension with 104 cells. This plate was put into an incubator at $37^{\circ} \mathrm{C}$ in a humidified atmosphere of $95 \%$ air and $5 \% \mathrm{CO}_{2}$ for periods of $2,4,7$, and 10 days. The DMEM was refreshed every 3 days. After the desired incubation period, sterile MTT solution of $10 \mu \mathrm{L}$ was added to each well and kept for a further 4 hours to obtain insoluble formazan crystals. Finally, $100 \mu \mathrm{L}$ of $10 \%$ sodium dodecyl sulfate $0.01 \mathrm{M} \mathrm{HCl}$ was added to each well to dissolve formazan crystals. The light absorbance in each well was determined at $570 \mathrm{~nm}$ using a multimode detector (DTX 880; Beckman Coulter, Pasadena, CA, USA), with a background correction at $640 \mathrm{~nm}$. The well with $100 \mu \mathrm{L}$ cell suspension and the well without cells (DMEM only) were employed as the positive and negative controls, respectively. The number of samples for each material in the tests was five, and the MTT assay tests were repeated at least twice. Data were reported as means and standard deviation.

\section{Results and discussion Structural and morphological analyses}

Figure 1 shows the XRD patterns of PP and PP-based composites. Pristine PP is characterized by diffraction peaks at $2 \theta=14.1^{\circ}, 16.9^{\circ}, 18.5^{\circ}, 21.2^{\circ}$, and $21.8^{\circ}$ associated with the (110), (040), (130), (111), and (041) reflections. The HANR peaks occur at $26.0^{\circ}, 28.3^{\circ}, 29.0^{\circ}$ $31.9^{\circ}, 33.0^{\circ}$, and $34.2^{\circ}$, corresponding to the (002), (102), (210), (211), (112), and (300) planes. It can be seen that the incorporation of CNF and/or HANR nanofillers into the polymer matrix does not induce structural change of the PP lattice. 


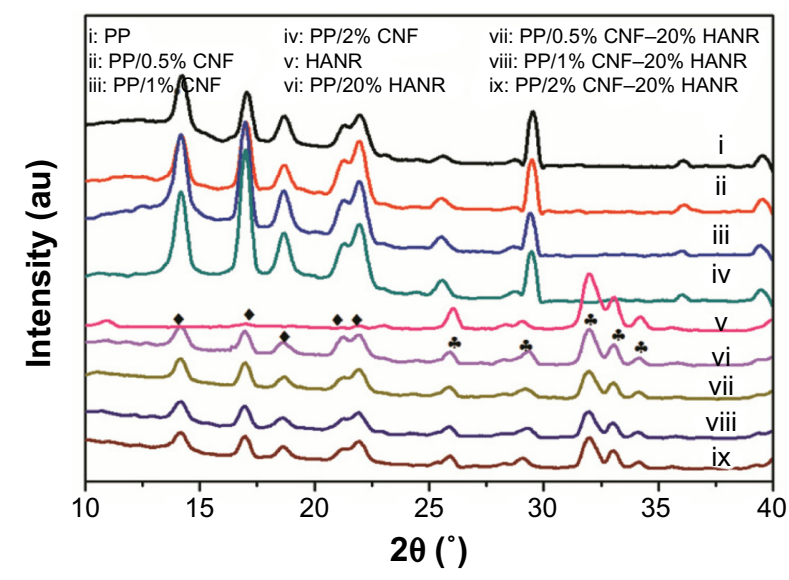

Figure I X-ray diffraction patterns of PP, HANR and their composites. Abbreviations: PP, polypropylene; CNF, carbon nanofiber; HANR, hydroxyapatite nanorod.

Figure 2 shows the FTIR spectra of PP and HANR and their composites. The absorption bands of the $\mathrm{PO}_{4}{ }^{3-}$ group of HANR (trace V) appear at 963 and $470 \mathrm{~cm}^{-1}\left(\gamma_{1}\right.$ and $\gamma_{2}$ vibration mode), 1,034 and 1,092 $\mathrm{cm}^{-1}\left(\gamma_{3}\right.$ mode of $\mathrm{P}-\mathrm{O}$ symmetric stretching vibration), and 565 and $601 \mathrm{~cm}^{-1}\left(\gamma_{4} \mathrm{P}-\mathrm{O}\right.$
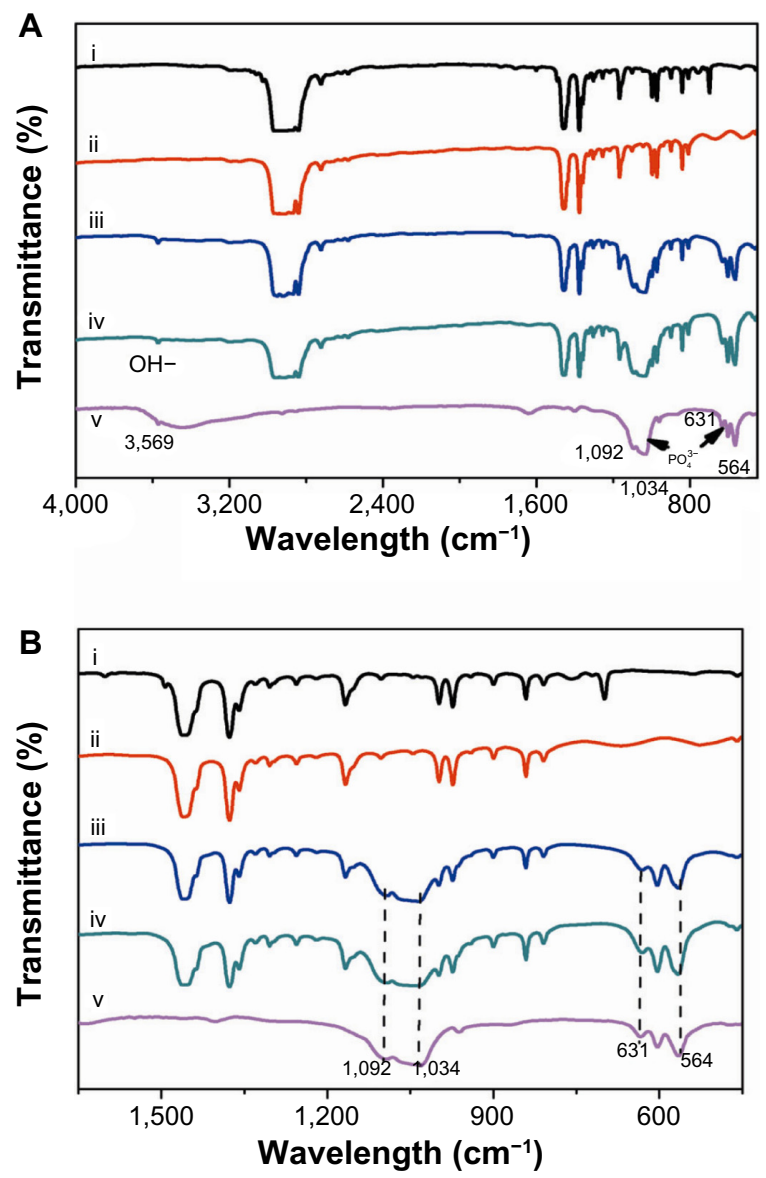

Figure 2 (A) Fourier-transform infrared spectra of PP (i), PP/I\% CNF (ii), PP/20\% nHA (iii), PP/I\% CNF-20\% nHA (iv), and nHA (v) specimens. (B) FTIR spectra of these specimens from 450 to $1,650 \mathrm{~cm}^{-1}$.

Abbreviations: PP, polypropylene; CNF, carbon nanofiber; HANR, hydroxyapatite nanorod; FTIR, fourier transform infrared. bending vibration). ${ }^{38}$ The peaks at 3,569 and $631 \mathrm{~cm}^{-1}$ are attributed to the hydroxide $(\mathrm{OH}-)$ stretching mode. The spectra of the PP $/ 20 \%$ HANR and PP $/ 1 \%$ CNF- $20 \%$ HANR nanocomposites reveal the presence of HANR with its phosphate-group peaks at $\sim 1,050,565$, and $601 \mathrm{~cm}^{-1}$, and the hydroxide-group band at $3,659 \mathrm{~cm}^{-1}$.

Figure 3 is a typical SEM image of CNFs showing a straight-rod morphology. Such CNFs supplied by Nanostructured and Amorphous Materials are used as the reinforcement material for PP to form composites. Figure 4A is the SEM image of PP/20\% HANR composite. Some HANR agglomerates can be observed due to its higher filler loading. The HANR content of $20 \mathrm{wt} \%$ is needed for anchoring and supporting the growth of osteoblasts. For the PP $/ 0.5 \% \mathrm{CNF}-20 \%$ HANR and $\mathrm{PP} / 2 \% \mathrm{CNF}-20 \%$ HANR hybrid composites, CNFs with straight features disperse uniformly in the PP matrix (Figure 4B and C).

\section{Thermal behavior}

Figure 5 shows the thermogravimetric analysis (TGA) curves of pure PP, binary PP/CNF, PP/20\% HANR, and ternary $\mathrm{PP} / \mathrm{CNF}-\mathrm{HANR}$ nanocomposites. The $T_{5 \%}$ values of all the specimens are tabulated in Table 2. This table reveals that the $T_{5 \%}$ of PP improves greatly either by adding $20 \%$ HANR or low CNF-loading levels. This demonstrates that both CNF and HANR nanofillers are very effective for reducing the degradation of PP at high temperatures. Furthermore, hybridization of CNFs with HANR fillers further enhances the $T_{5 \%}$ value of the resulting composites. The $\mathrm{PP} / 2 \% \mathrm{CNF}-20 \%$ HANR hybrid nanocomposite exhibits the highest $T_{5 \%}$ value of $444.6^{\circ} \mathrm{C}$. High $T_{5 \%}$ values are generally needed for biocomposites,

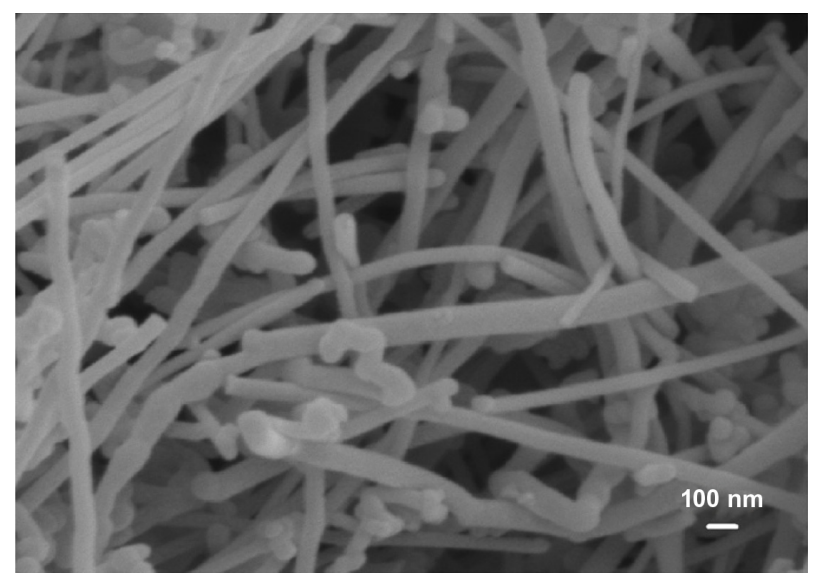

Figure 3 Scanning electron microscopy image of carbon nanofibers. 

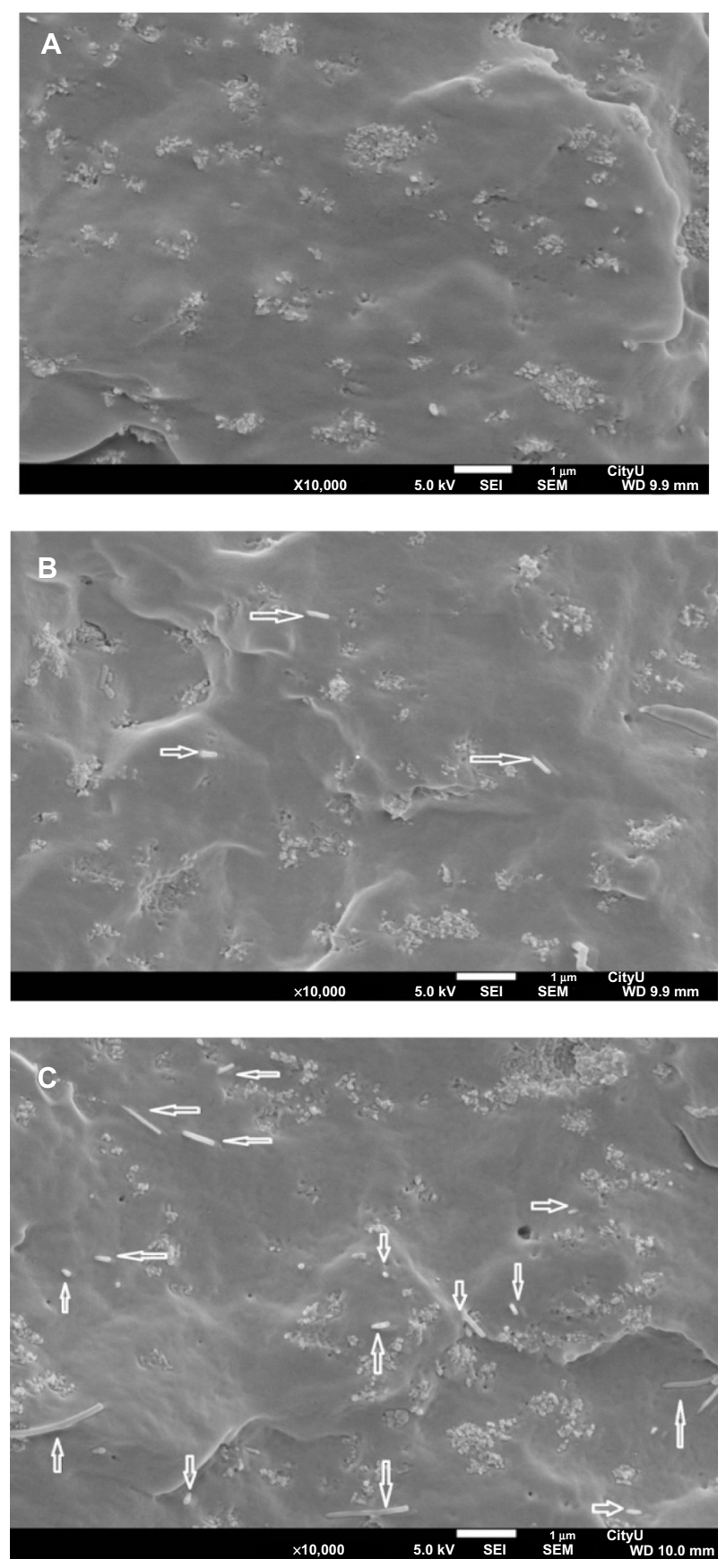

Figure 4 Scanning electron micrographs of PP/20\% HANR (A), PP/0.5\% CNF-20\% HANR (B), and PP/2\% CNF-20\% HANR (C) composites. White arrows indicate CNFs.

Abbreviations: PP, polypropylene; CNF, carbon nanofiber; HANR, hydroxyapatite nanorod.

since artificial implants are subjected to sterilization in the surgical operation.

Figure 6 shows the DSC cooling traces of PP, $\mathrm{PP} / 20 \%$ HANR, PP/CNF, and PP/CNF-HANR samples. The onset crystallization temperature (To), peak crystallization $(T c)$ temperature, and the crystallization enthalpy $(\Delta H c)$ are also listed in Table 2 . The degree of

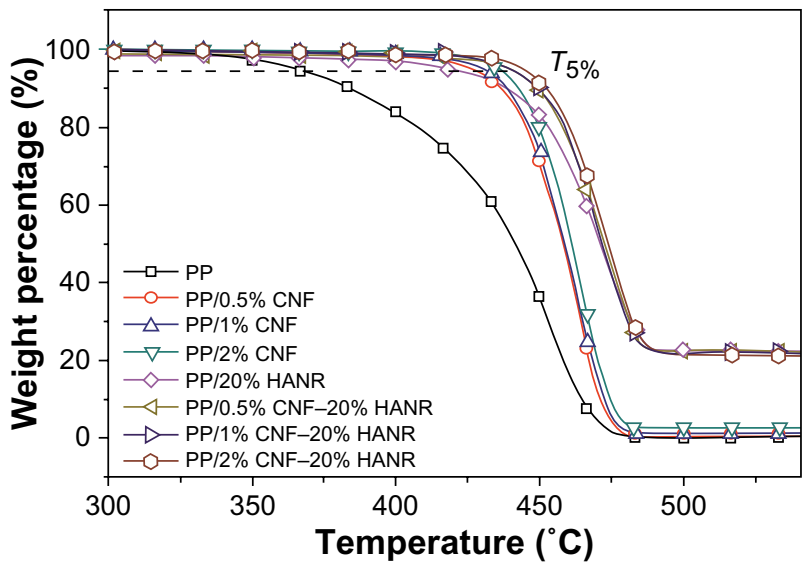

Figure 5 Thermogravimetric analysis curves of PP, PP/0.5\% CNF, PP/I\% CNF, PP/2\% CNF, PP/20\% HANR, PP/0.5\% CNF-20\% HANR, PP/I\% CNF-20\% HANR, and PP/2\% CNF-20\% HANR specimens.

Abbreviations: PP, polypropylene; CNF, carbon nanofiber; HANR, hydroxyapatite nanorod.

crystallinity $(X c)$ of PP and its nanocomposites can be determined from:

$$
X c(\%)=100 \frac{\Delta H c}{(1-f) \Delta H m}
$$

where $\Delta H m$ is the melting enthalpy of the $100 \%$ crystalline PP, ie, $209 \mathrm{~J} / \mathrm{g},{ }^{39,40}$ and $f$ is the weight fraction of the filler of the nanocomposites. For pure PP, $f=0$. The DSC parameters of the aforementioned specimens are tabulated in Table 2. Apparently, DSC results clearly demonstrate that the HANR and CNF additions influence crystallization of PP greatly. Both the $T o$ and $T c$ values of PP increase considerably with the inclusion of $\mathrm{CNF}$ and/or HANR nanofillers. The $T o$ value of pure $\mathrm{PP}$ is $115.1^{\circ} \mathrm{C}$, and rises to $123.9^{\circ} \mathrm{C}$ by adding $20 \mathrm{wt} \%$ HANR. The $T c$ value of PP $/ 20 \%$ HANR nanocomposite can be further increased to $125.5^{\circ} \mathrm{C}$ by adding $2 \mathrm{wt} \% \mathrm{CNFs}$. The $X c$ value of PP is almost unchanged by adding $20 \mathrm{wt} \%$ HANR. However, the additions of $0.5-2 \mathrm{wt} \%$ CNFs to the

Table 2 Thermal parameters of the samples investigated

\begin{tabular}{|c|c|c|c|c|c|}
\hline Specimen & $\begin{array}{l}\text { To } \\
\left({ }^{\circ} \mathrm{C}\right)\end{array}$ & $\begin{array}{l}\text { Tc } \\
\left({ }^{\circ} \mathrm{C}\right)\end{array}$ & $\begin{array}{l}\Delta H c \\
(\mathrm{~J} / \mathrm{g})\end{array}$ & $\begin{array}{l}X c \\
\text { (\%) }\end{array}$ & $\begin{array}{l}T_{5 \%} \\
\left({ }^{\circ} \mathrm{C}\right)\end{array}$ \\
\hline PP & 115.1 & 111.6 & 94.8 & 45.3 & 365.2 \\
\hline $\mathrm{PP} / 0.5 \% \mathrm{CNF}$ & 124.4 & 120.9 & 96.5 & 46.4 & 427.1 \\
\hline $\mathrm{PP} / \mathrm{I} \% \mathrm{CNF}$ & 124.5 & 121.4 & 97.2 & 46.9 & 431.0 \\
\hline $\mathrm{PP} / 2 \% \mathrm{CNF}$ & 124.5 & 121.4 & 95.0 & 46.3 & 436.1 \\
\hline PP/20\% HANR & 123.9 & 119.7 & 75.5 & 45.1 & 424.6 \\
\hline PP/0.5\% CNF-20\% HANR & 124.5 & 121.1 & 81.4 & 48.9 & 440.1 \\
\hline PP/I\% CNF-20\% HANR & 124.8 & 120.7 & 77.9 & 47.2 & 441.3 \\
\hline PP $/ 2 \%$ CNF-20\% HANR & 125.5 & 121.7 & 78.4 & 48.1 & 444.6 \\
\hline
\end{tabular}

Abbreviations: PP, polypropylene; CNF, carbon nanofiber; HANR, hydroxyapatite nanorod; To, onset crystallization temperature, $T c$, peak crystallization temperature; $\Delta H c$, crystallization enthalpy; $X c$, degree of crystallinity; $T_{5 \%}$, temperature at $5 \%$ weight loss. 


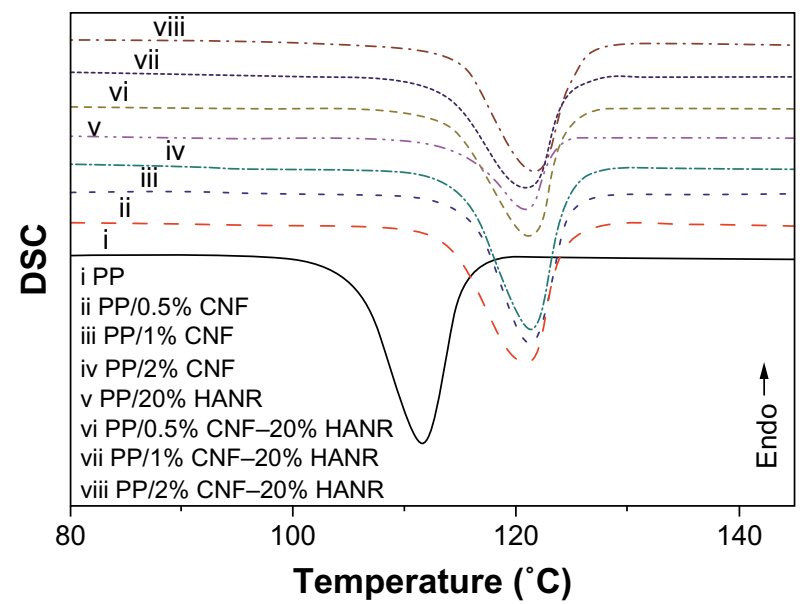

Figure 6 Differential scanning calorimetry (DSC) cooling curves of PP, PP/0.5\% CNF, PP/I\% CNF, PP/2\% CNF, PP/20\% HANR, PP/0.5\% CNF-20\% HANR, PP/I\% CNF-20\% HANR, and PP/2\% CNF-20\% HANR specimens.

Abbreviations: PP, polypropylene; CNF, carbon nanofiber; HANR, hydroxyapatite nanorod.

$\mathrm{PP} / 20 \%$ HANR nanocomposites increase its crystallinity. Therefore, CNF nanofillers are effective nucleating sites for PP crystallites in the PP/HANR composites upon cooling from the melt.

\section{Mechanical properties}

Figure 7A and $\mathrm{B}$ show the elastic modulus and tensile strength versus $\mathrm{CNF}$ content for the $\mathrm{PP} / \mathrm{CNF}$ and $\mathrm{PP} / \mathrm{CNF}-\mathrm{HANR}$ composite systems, respectively. The tensile properties of these specimens are summarized in Table 3. It is obvious that the stiffness of PP increases with increasing CNF content. Furthermore, the stiffness of PP increases markedly from $1.36 \mathrm{GPa}$ to $2.28 \mathrm{GPa}$ by adding $20 \mathrm{wt} \%$ HANR (6.67 vol $\%$ ), being $67.6 \%$ improvement. Higher HANR content is added to PP with bioinertness for anchoring and proliferation of osteoblasts on its surface. Hybridization of CNF with HANR further enhances the stiffness of PP. The PP $/ 2 \%$ CNF- $20 \%$ HANR hybrid exhibits a maximum stiffness value of $2.52 \mathrm{GPa}$, an $85.2 \%$ enhancement over pure PP.

Liu and Wang investigated the tensile behavior of PP/10-25 vol\% HA $(24.5 \mu \mathrm{m})$ composites. ${ }^{41}$ They found that the Young's modulus of PP (1.30 GPa) increases with HA content up to $25 \mathrm{vol} \%$. The stiffness of the PP $/ 25 \mathrm{vol} \% \mathrm{HA}$ composite reaches $2.73 \mathrm{GPa}$. However, the tensile strength of PP (ie, $29.55 \mathrm{MPa}$ ) and elongation at fracture decrease markedly with increasing filler content. At $25 \mathrm{vol} \% \mathrm{HA}$, the tensile strength reduces to $20.16 \mathrm{MPa}$. These results clearly show that large HA particles of micrometer size are ineffective to improve the PP tensile strength.

From Table 3, the modulus and tensile strength of $\mathrm{PP} / 20 \mathrm{wt} \%$ (6.67 vol\%) HANR nanocomposite are $2.28 \mathrm{GPa}$
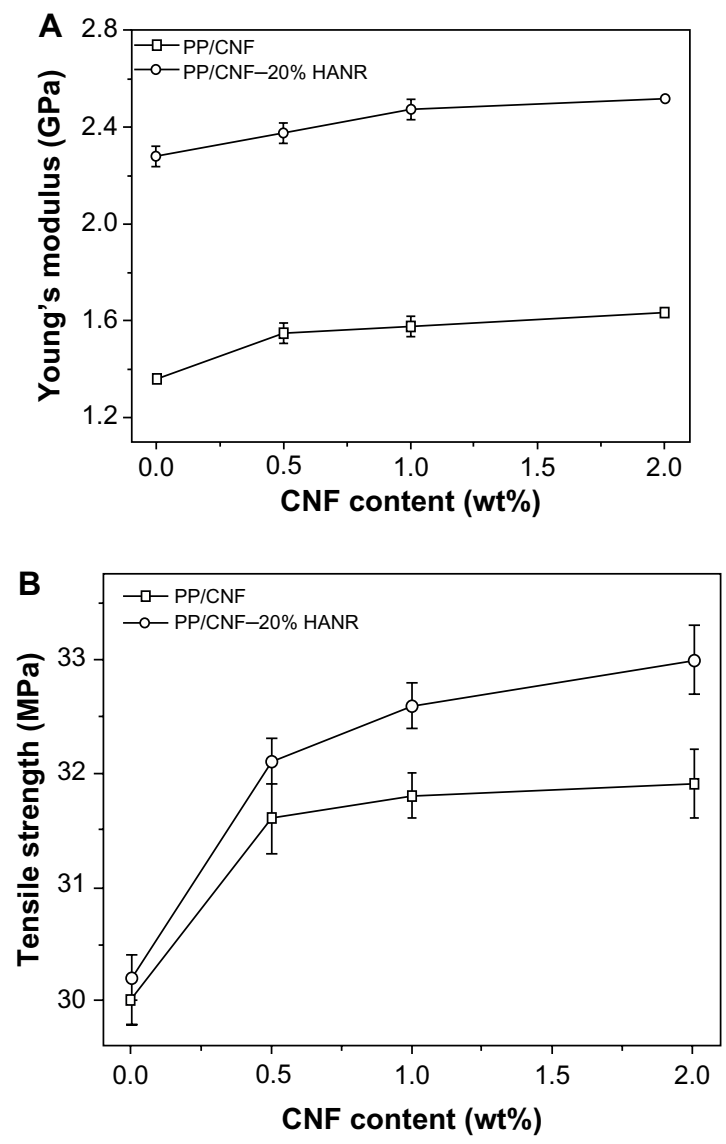

Figure 7 Young's modulus (A) and tensile strength (B) versus CNF content of PP/ CNF and PP/CNF-20\% HANR systems.

Abbreviations: PP, polypropylene; CNF, carbon nanofiber; HANR, hydroxyapatite nanorod.

and $30.2 \mathrm{MPa}$, respectively. The stiffness of this nanocomposite is slightly smaller than that of the $\mathrm{PP} / 25 \mathrm{vol} \% \mathrm{HA}$ microcomposite, but the tensile strength is much higher than that of the PP/25 vol\% HA microcomposite. It should be noted that the filler content of the PP/6.67 vol\% HANR nanocomposite

Table 3 Mechanical properties of PP-based composites

\begin{tabular}{|c|c|c|c|c|}
\hline Sample & $\begin{array}{l}\text { Young's } \\
\text { modulus, } \\
\text { MPa }\end{array}$ & $\begin{array}{l}\text { Tensile } \\
\text { strength, } \\
\mathrm{MPa}\end{array}$ & $\begin{array}{l}\text { Elongation, } \\
\%\end{array}$ & $\begin{array}{l}\text { Impact } \\
\text { strength, } \\
\text { kJ m-2 }\end{array}$ \\
\hline PP & $1,360 \pm 20$ & $30.0 \pm 0.2$ & $>500$ & $2.18 \pm 0.08$ \\
\hline $\mathrm{PP} / 0.5 \%$ CNF & I,548 \pm 42 & $31.6 \pm 0.3$ & $>500$ & $2.82 \pm 0.14$ \\
\hline $\mathrm{PP} / \mathrm{I} \% \mathrm{CNF}$ & $1,574 \pm 33$ & $31.8 \pm 0.2$ & $>500$ & $2.84 \pm 0.11$ \\
\hline $\mathrm{PP} / 2 \%$ CNF & $1,630 \pm 25$ & $31.9 \pm 0.3$ & $>500$ & $2.98 \pm 0.18$ \\
\hline PP/20\% HANR & $2,280 \pm 40$ & $30.2 \pm 0.2$ & $8.7 \pm 0.9$ & $1.53 \pm 0.06$ \\
\hline $\mathrm{PP} / 0.5 \%$ & $2,377 \pm 48$ & $32.1 \pm 0.2$ & $10.5 \pm 0.9$ & $2.21 \pm 0.07$ \\
\hline CNF- $20 \%$ HANR & & & & \\
\hline PP/I\% & $2,473 \pm 47$ & $32.6 \pm 0.2$ & $8.7 \pm 0.8$ & $2.30 \pm 0.12$ \\
\hline CNF-20\% HANR & & & & \\
\hline $\begin{array}{l}\text { PP/2\% } \\
\text { CNF-20\% HANR }\end{array}$ & $2,517 \pm 15$ & $33.0 \pm 0.3$ & $7.7 \pm 0.2$ & $2.38 \pm 0.19$ \\
\hline
\end{tabular}

Abbreviations: PP, polypropylene; CNF, carbon nanofiber; HANR, hydroxyapatite nanorod. 
is nearly a quarter less than that of the $\mathrm{PP} / 25 \mathrm{vol} \% \mathrm{HA}$ microcomposite. When $2 \mathrm{wt} \% \mathrm{CNF}$ is added to the $\mathrm{PP} / 20 \mathrm{wt} \%$ (6.67 vol\%) HANR nanocomposite, its modulus and tensile strength reaches $2.52 \mathrm{GPa}$ and $33.0 \mathrm{MPa}$, respectively. This table also reveals that the elongation at break of PP $(>500 \%)$ decreases sharply with the addition of rigid HANR. For the $\mathrm{PP} / 20 \mathrm{wt} \%$ HANR, the elongation reduces to only $8.7 \%$. In contrast, the addition of $0.5-2 \mathrm{wt} \% \mathrm{CNFs}$ to PP does not lead to a deterioration of its fracture elongation. The $\mathrm{PP} / \mathrm{CNF}$ nanocomposites still retain high tensile ductility $(>500 \%)$.

Figure 8 shows the Izod impact strength versus CNF content for the PP/CNF and PP/CNF-20\% HANR nanocomposite systems. The Izod test results of the specimens investigated are listed in Table 3. Obviously, the impact strength of PP improves considerably as the CNF loading increases. However, the impact toughness of PP reduces markedly to $1.53 \mathrm{~kJ} \mathrm{~m}^{2}$ by adding $20 \mathrm{wt} \%$ HANR. The toughness of the $\mathrm{PP} / 20 \%$ HANR composite can be restored by $\mathrm{CNF}$ additions. The impact strength of $\mathrm{PP} / \mathrm{CNF}-20 \% \mathrm{HANR}$ containing $0.5-2 \mathrm{wt} \% \mathrm{CNFs}$ ranges from 2.21 to $2.38 \mathrm{~kJ} \mathrm{~m}^{-2}$, higher than that of PP, having a value of $2.18 \mathrm{~kJ} \mathrm{~m}^{-2}$.

It is generally known that several mechanical failure modes, such as fiber breakage, crack bridging, crack deflection, and fiber pullout will take place in polymer composites filled with short fibers. In general, crack bridging contributes to an enhancement in the toughness of such microcomposites greatly. During mechanical deformation, the propagating crack is bridged by the fibers that are not fractured completely and capable of load-bearing activity. Apparently, CNFs with large aspect ratios can behave as carbon short fibers that bridge the grown cracks, leading

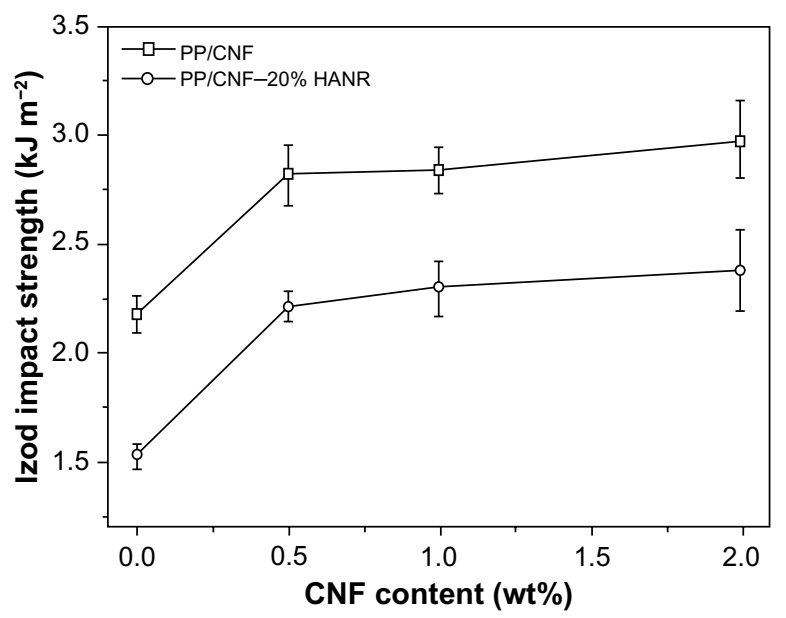

Figure 8 Impact strength versus CNF content of PP/CNF and PP/CNF-20\% HANR systems.

Abbreviations: PP, polypropylene; CNF, carbon nanofiber; HANR, hydroxyapatite nanorod. to enhanced tensile elongation and impact strength of the $\mathrm{PP} / \mathrm{CNF}$ and $\mathrm{PP} / \mathrm{CNF}-20 \%$ HANR nanocomposite systems, as shown in Figure 8 and Table 3.

From these results, it appears that the CNF additions are beneficial for enhancing tensile modulus and tensile strength of the PP $/ 20 \%$ HANR composite (Figure $7 \mathrm{~A}$ and B). Moreover, $\mathrm{CNF}$ additions do not degrade tensile elongation or impact toughness of the PP/CNF-20\% HANR nanocomposite system, but rather improve them. The mechanical properties of the hybrid composites are closely related to their microstructural features, especially the dispersion of nanofillers. Microstructural examination of the hybrid composites reveals that straight CNFs are dispersed homogeneously in the polymer matrix (Figure 4B and C). In other words, CNFs do not cluster into agglomerates that degrade mechanical performance of the composites. On the contrary, CNTs are well known to disperse nonuniformly in the polymer composites. Accordingly, uniformly dispersed CNFs can carry applied loads effectively during tensile tests, leading to enhanced tensile properties of the PP/CNF-20\% HANR nanocomposite system.

\section{Cell cultivation and viability}

Figure 9A and B are respective SEM images of pure PP cultivated with osteoblasts for 2 and 4 days. Very few cells are anchored on PP, as expected due to its bioinertness. By adding CNFs to PP, the number of anchored cells increases (Figures 10 and 11 ), particularly for the $\mathrm{PP} / 2 \% \mathrm{CNF}$ nanocomposite cultured for 4 days (Figure 11B). This implies that CNFs serve as preferential regions for anchoring osteoblasts. This is due to the good bioactivity and biocompatibility of the CNFs. ${ }^{14,15}$ Similarly, a large number of osteoblasts are seen to anchor on the PP/20\% HANR composite (Figure 12), demonstrating the promotion effect of osteoblast adhesion by inorganic HANR fillers. By combining the bioactivity advantages of both CNFs and HANR, the cells colonize the hybrid-composite surfaces (Figures 13A and 14A) and spread over the whole surfaces after seeding for 4 days (Figures 13B and 14B). A highmagnification view of osteoblast cells showing the anchoring of long filopodia to the composite surface is shown in Figure 14C. This implies that the hybrid fillers provide sites for cell adhesion and proliferation.

The good bioactivity and biocompatibility of the CNFs are attributed to their nanoscale dimensions. The size of CNFs resembles the dimension of collagen fibrils and protein components of human bones. Price at al investigated the effects of dimension, surface energy, and chemistry of carbon fibers on selective bone cell adhesion. ${ }^{20}$ 

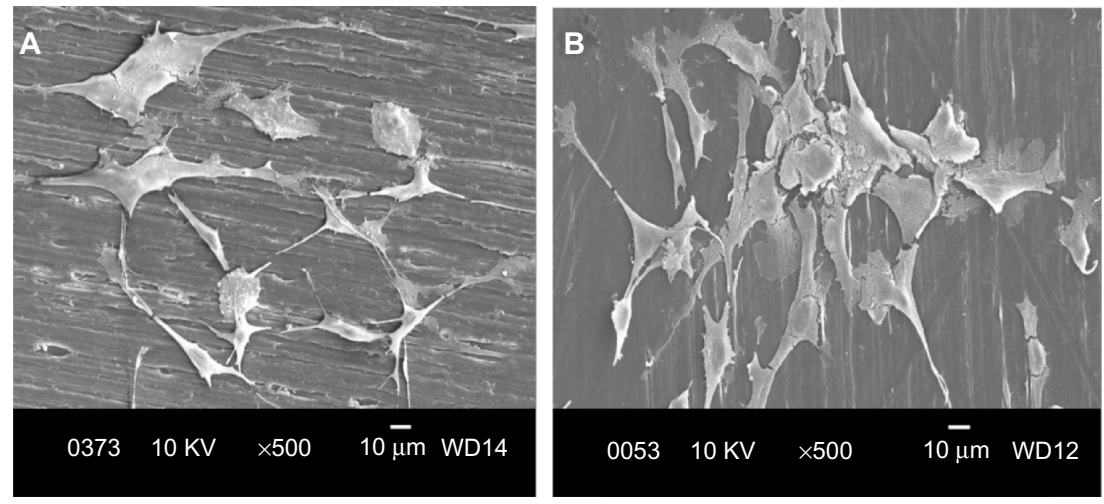

Figure 9 Scanning electron micrographs of cultured osteoblasts on pure PP for 2 days (A) and 4 days (B). Abbreviation: PP, polypropylene; KV, kilo volt; WD, working distance.
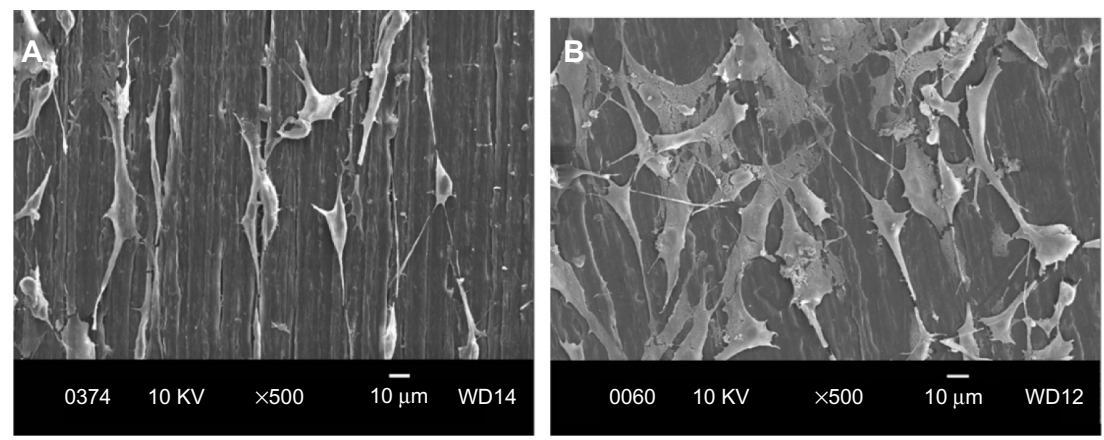

Figure 10 Scanning electron micrographs of cultured osteoblasts on PP/0.5\% CNF composite for 2 days (A) and 4 days (B). Abbreviations: PP, polypropylene; CNF, carbon nanofiber; KV, kilo volt; WD, working distance.
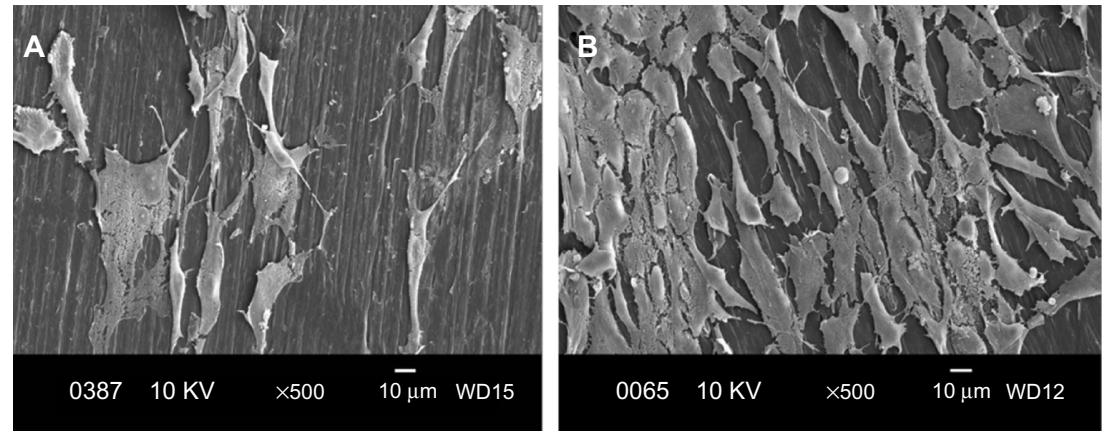

Figure II Scanning electron micrographs of cultured osteoblasts on PP/2\% CNF composite for 2 days (A) and 4 days (B).

Abbreviations: PP, polypropylene; CNF, carbon nanofiber; KV, kilo volt; WD, working distance.
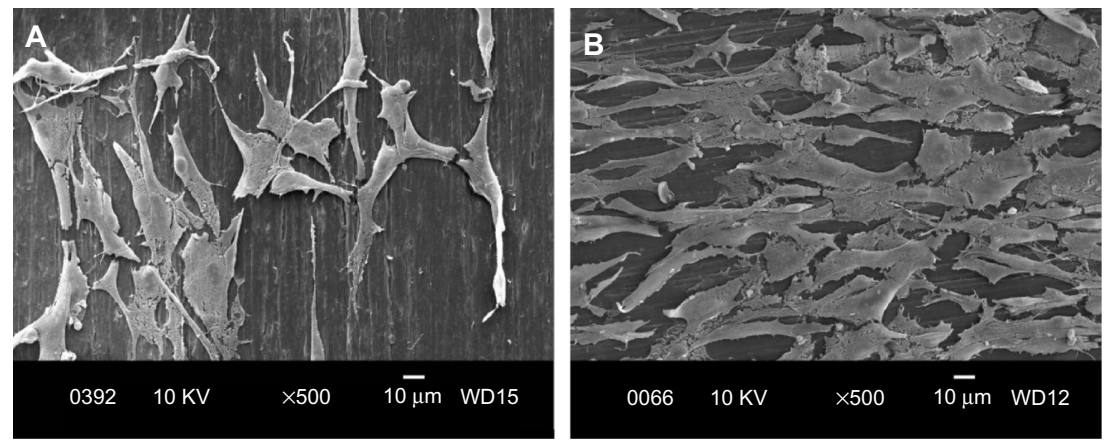

Figure 12 Scanning electron micrographs of cultured osteoblasts on PP/20\% HANR composite for 2 days (A) and 4 days (B).

Abbreviations: PP, polypropylene; HANR, hydroxyapatite nanorod; KV, kilo volt; WD, working distance. 

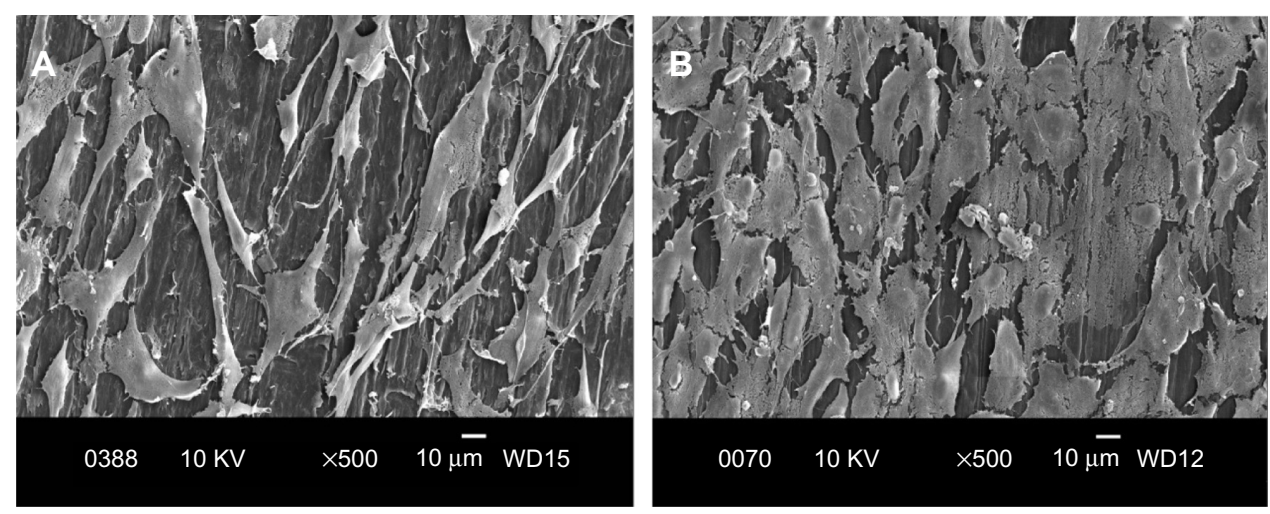

Figure 13 Scanning electron micrographs of cultured osteoblasts on PP/0.5\% CNF-20\% HANR hybrid composite for 2 days (A) and 4 days (B). Abbreviations: PP, polypropylene; CNF, carbon nanofiber; HANR, hydroxyapatite nanorod; KV, kilo volt; WD, working distance.

They reported that CNFs with diameters $<100 \mathrm{~nm}$ are more effective than carbon fibers with diameters $>100 \mathrm{~nm}$ and other metallic alloys (Ti-6Al-4V and CoCrMo) for promoting osteoblast adhesion. Furthermore, CNFs without pyrolytic layers having higher surface energy exhibit enhanced osteoblastic adhesion, but reduce the seeding of fibroblasts, chondrocytes, and smooth-muscle cells. As recognized, the adhesion of osteoblasts onto nanomaterials is mediated through selected protein interaction, such as with integrin. ${ }^{22}$ Zhang and Webster demonstrated that nanomaterials with favorable cell-surface characteristics promote extensive protein interaction and adhesion, thereby stimulating bone growth. ${ }^{15}$

From the literature, attachment, adhesion, and spreading in bone implants are required for osteogenic cells to proliferate on their surfaces. ${ }^{42}$ The MTT assay has been recommended by the International Standards Organization (ISO) for the evaluation of biocompatibility of medical
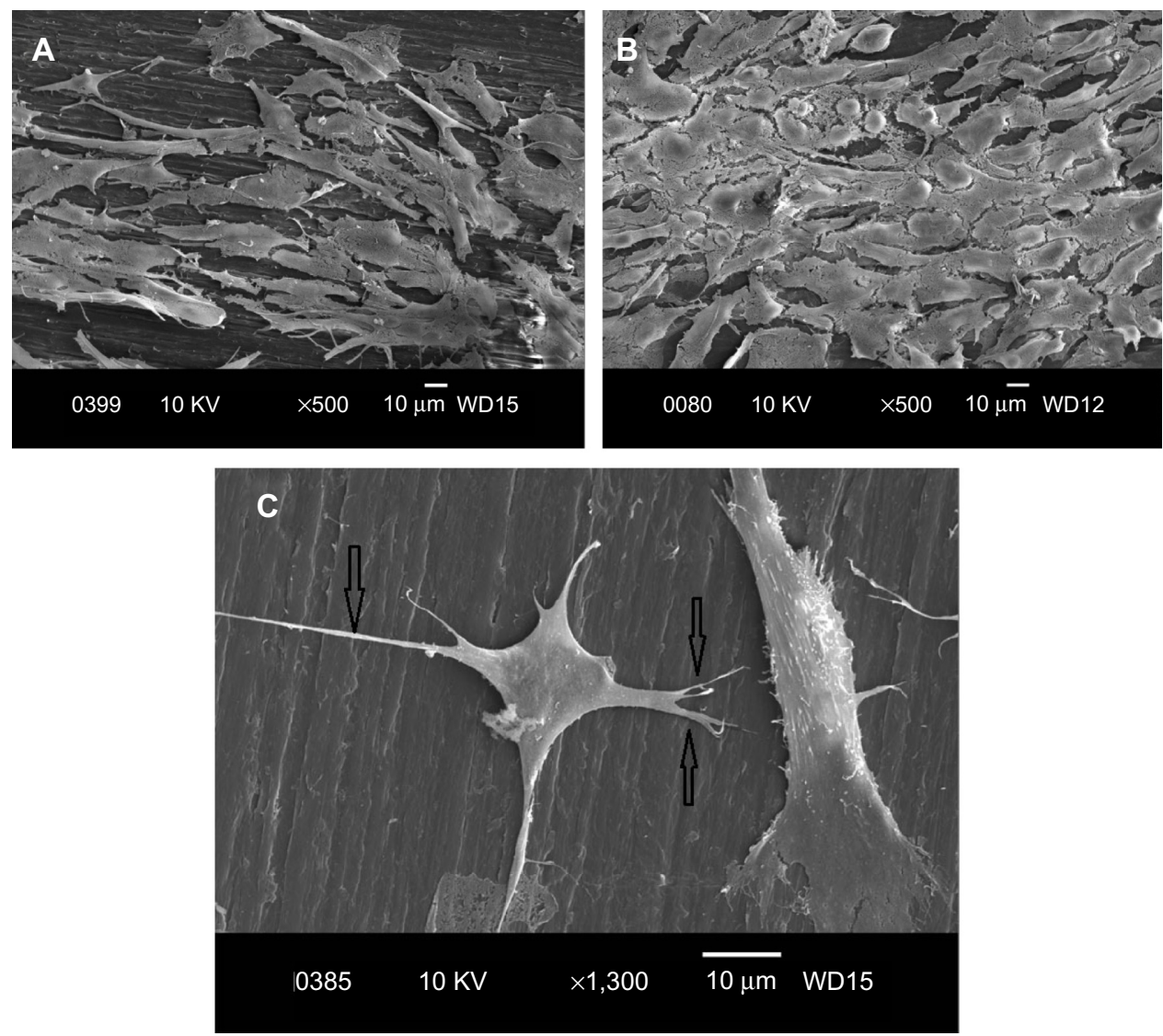

Figure I4 Scanning electron micrographs of cultured osteoblasts on PP/2\% CNF-20\% HANR hybrid composite for 2 days (A) and 4 days (B). (C) High magnified SE image showing long filopodias.

Abbreviations: PP, polypropylene; CNF, carbon nanofiber; HANR, hydroxyapatite nanorod; KV, kilo volt; WD, working distance. 
devices, ie, ISO 10993-5. ${ }^{43}$ The evaluation of cell viability should encompass a negative control testing the absence of cytotoxic effects; ISO109935-1 recommends high-density polyethylene. ${ }^{44}$ In this study, the well with cell suspension and the well without cells were employed as the positive and negative controls, respectively.

Cellular viability is determined from the following equation:

$$
\text { Cell viability }(\%)=100\left[\frac{\text { absorbance of sample cells }}{\text { absorbance of control cells }}\right] \text {. }
$$

Figure $15 \mathrm{~A}$ shows the MTT results for pure PP, PP/20\% HANR, PP/0.5\% CNF, and PP/0.5\% CNF-20\% HANR specimens cultivated for $2,4,7$, and 10 days. The osteoblast viability for the $\mathrm{PP} / 2 \% \mathrm{CNF}$ and $\mathrm{PP} / 2 \% \mathrm{CNF}-20 \%$ HANR composites with higher CNF content is shown in Figure 15B. From Figure 15A, the osteoblast viability on these samples rises with increasing cultivation period up
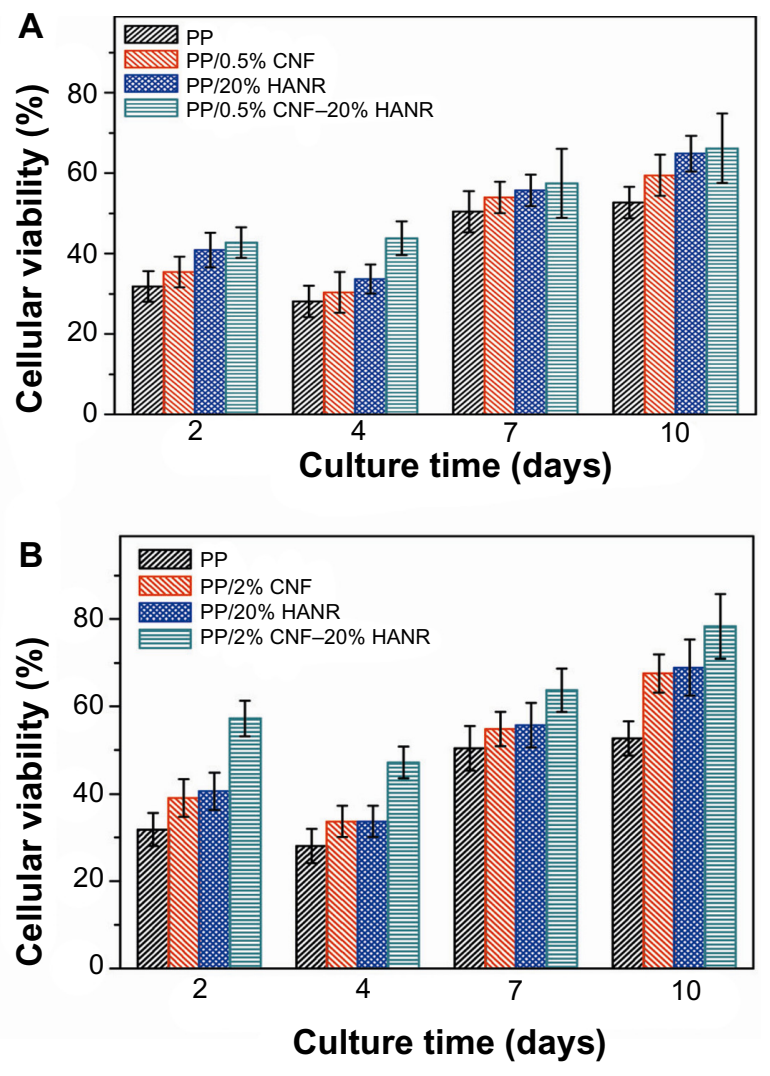

Figure 15 Cell viability of cultured osteoblasts on PP, PP/20\% HANR, PP/20\% HANR, PP/CNF, and PP/CNF-HANR nanocomposites. Error bars represent mean standard deviation of five identical specimens.

Abbreviations: PP, polypropylene; CNF, carbon nanofiber; HANR, hydroxyapatite nanorod. to 10 days. For pure PP, the cell viability is slightly below $30 \%$ after 4 days of culture, corresponding to cytotoxicity effects. The viability of $\mathrm{PP} / 0.5 \% \mathrm{CNF}-20 \% \mathrm{HANR}$ is $45 \%$ after 4 days and reaches $68 \%$ upon cultivation for 10 days. By increasing CNF content in the hybrid to $2 \mathrm{wt} \%$, the $\mathrm{PP} / 2 \% \mathrm{CNF}-20 \% \mathrm{HANR}$ composite is found to exhibit the highest osteoblast viability on day $10-78 \%$. Therefore, the cell viability of PP can be improved markedly by adding 2\% CNF and 20\% HANR fillers. The MTT results for all samples cultured for 4 and 10 days are summarized in Figure 16.

For the MTT assay, the amount of formazan crystals produced is directly proportional to the number of metabolically active cells in the culture. However, this assay can yield lower cell-viability values upon cultivation with CNTs. Wörle-Knirsch et al exposed the human alveolar epithelial cell line A549 to single-walled CNTs and reported that the MTT assay produces considerable loss in cell viability, due to the MTT formazan crystals clumping together with CNTs. Such a lumped formazan-CNT mixture dissolves poorly in organic solvents, eg, propanol/ $\mathrm{HCl}$ or acetone. ${ }^{45}$ This interference does not affect the enzymatic reaction, but results from the insoluble nature of MTT formazan crystals. However, the salt (2-[4-iodophenyl]-3-[4-nitrophenyl]-5 -[2,4-disulfophenyl]-2H-tetrazolium) used in the WST-1 assay can yield a water-soluble formazan product, and thus no solvent extraction is needed. From the MTT results, the $\mathrm{PP} / 2 \% \mathrm{CNF}-20 \%$ HANR hybrid exhibits the highest cellular viability. It is considered that the interference of CNF on MTT test results causes a reduction in cell viability. More extensive investigations should be done in future to elucidate this issue by employing other cell-viability assays.

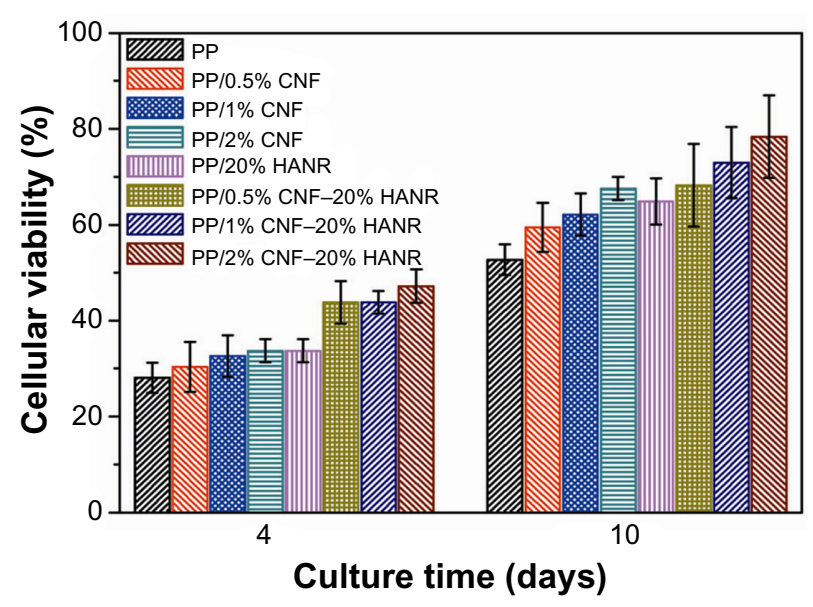

Figure 16 Cell viability of cultured osteoblasts on PP and its nanocomposites. Abbreviations: PP, polypropylene; CNF, carbon nanofiber; HANR, hydroxyapatite nanorod. 


\section{Conclusion}

We fabricated $\mathrm{PP} / \mathrm{CNF}$ nanocomposites and $\mathrm{PP} / \mathrm{CNF}-20 \%$ HANR hybrids using melt-compounding and injectionmolding processes. The influences of low CNF loadings on the microstructural, mechanical, and thermal properties as well as the cellular viability of PP were investigated. The results show that $\mathrm{CNF}$ additions improve the elastic modulus and tensile strength of PP without sacrificing its tensile ductility and impact toughness. Further enhancement in tensile properties of PP can be achieved by hybridizing CNF with HANR fillers. The PP/2\% CNF-20\% HANR hybrid shows highest stiffness and tensile strength. TGA tests reveal that the thermal stability of PP improves markedly either by adding 20\% HANR or low CNF-loading levels. The PP/2\% CNF-20\% HANR hybrid also exhibits the highest $T_{5 \%}$ value of $444.6^{\circ} \mathrm{C}$. DSC measurements indicate that CNFs act as effective nucleating sites for PP crystallites upon cooling from the melt. Finally, CNF nanofillers promote osteoblastic adhesion and viability on PP. The MTT results reveal that the $\mathrm{PP} / 2 \% \mathrm{CNF}-20 \%$ HANR hybrid exhibits good biocompatibility for osteoblasts.

\section{Acknowledgment}

This work was supported by an Applied Research Grant (9667071), City University of Hong Kong.

\section{Disclosure}

The authors report no conflicts of interest in this work.

\section{References}

1. Yu J, Zhao ZJ, Li LX. Corrosion fatigue resistances of surgical implant stainless steels and titanium alloy. Corros Sci. 1993;35(1-4): 587-591.

2. Metikas-Huković M, Kwokal A, Piljac J. The influence of niobium and vanadium on passivity of titanium-based implants in physiological solution. Biomaterials. 2003;24(21):3765-3775.

3. Kim TI, Han JH, Lee IS, Lee KH, Shin MC, Choi BB. New titanium alloys for biomaterials: a study of mechanical and corrosion properties and cytotoxicity. Biomed Mater Eng. 1997;7(4):253-263.

4. Tjong SC, Lau KC. Properties and abrasive wear of TiB2/A1-4\%Cu composites produced by hot isostatic pressing. Compos Sci Technol. 1999;59(13):2005-2013.

5. Hench LL, Wilson J. An Introduction to Bioceramics. Singapore: World Scientific; 1993.

6. Roeder RK, Converse GL, Kane RJ, Yue W. Hydroxyapatitereinforced polymer biocomposites for synthetic bone substitutes. JOM. 2008;60(3):38-45.

7. Sachlos E, Wahl DA, Triffitt JT, Czernuszka JT. The impact of critical point drying with liquid carbon dioxide on collagen-hydroxyapatite composite scaffolds. Acta Biomater. 2008;4(5):1322-1331.

8. Ngiam M, Liao SS, Patil AJ, Cheng ZY, Chan CK, Ramakrishna S. The fabrication of nano-hydroxyapatite on PLGA and PLGA/collagen nanofibrous composite scaffolds and their effects in osteoblastic behavior for bone tissue engineering. Bone. 2009;45(1):4-16.
9. Huang J, Disilvio L, Wang M, Tanner KE, Bonfield W. In vitro mechanical and biological assessment of hydroxyapatite-reinforced polyethylene composite. J Mater Sci Mater Med. 1997;8(12):775-779.

10. Guild FJ, Bonfield W. Predictive modelling of the mechanical properties and failure processes in hydroxyapatite-polyethylene (HapexTM) composite. J Mater Sci Mater Med. 1998;9(9):497-502.

11. Wang M, Joseph R, Bonfield W. Hydroxyapatite-high density polyethylene composites: effect of ceramic particle size and morphology. Biomaterials. 1998;19(24):2357-2366.

12. Abu Bakar MS, Cheang P, Khor KA. Mechanical properties of injection molded hydroxyapatite-polyetheretherketone biocomposites. Compos Sci Technol. 2003;63(3-4):421-425.

13. Tjong SC, Chen H. Nanocrystalline materials and coatings. Mater Sci Eng R Rep. 2004;45(1-2):1-88.

14. Yang L, Zhang LJ, Webster TJ. Nanobiomaterials: state of the art and future trends. Adv Eng Mater. 2011;13(6):B197-B217.

15. Zhang LJ, Webster TJ. Nanotechnology and nanomaterials: promises for improved tissue regeneration. Nano Today. 2009;4(1):66-80.

16. Ergun C, Liu HN, Halloran JW, Webster TJ. Increased osteoblast adhesion on nanograined hydroxyapatite and tricalcium phosphate containing calcium titanate. J Biomed Mater Res A. 2007;80(4): 990-997.

17. Li K, Tjong SC. Hydrothermal synthesis and bio-mineralization of hydroxyapatite nanorods. J Nanosci Nanotechnol. 2011;11: 10444-10448.

18. Zhou H, Lee J. Nanoscale hydroxyapatite particles for bone tissue engineering. Acta Biomater. 2011;7(7):2769-2781.

19. Smart SK, Cassady AI, Lu G, Martin DJ. The biocompatibility of carbon nanotubes. Carbon. 2006;44(6):1034-1047.

20. Price RL, Waid M, Haberstroh K, Webster TJ. Selective bone cell adhesion on formulations containing carbon nanofibers. Biomaterials. 2003;24(11):1877-1887.

21. Li XM, Gao H, Uo M, et al. Effect of carbon nanotubes on cellular functions in vitro. J Biomed Mater Res A. 2009;91A(1):132-139.

22. Newman P, Minett A, Ellis-Behnke R, Zreiqat H. Carbon nanotubes: their potential and pitfalls for bone tissue regeneration and engineering. Nanomedicine. 2013;9(8):1139-1158.

23. Li K, Yeung Yeung CY, Yeung KW, Tjong SC. Sintered hydroxyapatite/ polyetheretherketone nanocomposites: mechanical behavior and biocompatibility. Adv Eng Mater. 2012;14(4):B155-B165.

24. Li K, Tjong SC. Mechanical, thermal and bioactive behaviors of polyamide 6/hydroxyapatite nanocomposites. J Nanosci Nanotechnol. 2011;11(12):10644-10648.

25. Liao CZ, Li K, Wong HM, Tong WY, Yeung KW, Tjong SC. Novel polypropylene biocomposites reinforced with carbon nanotubes and hydroxyapatite nanorods for bone replacements. Mater Sci Eng C Mater Biol Appl. 2013;33(3):1380-1388.

26. Tjong SC. Structural and mechanical properties of polymer nanocomposites. Mater Sci Eng R Rep. 2006;53(3-4):73-197.

27. Gilmore KJ, Moulton SE, Wallace GG. Incorporation of carbon nanotubes into the biomedical polymer poly(styrene- $\beta$-isobutylene$\beta$-styrene). Carbon. 2007;45(2):402-410.

28. Kumar NA, Ganapathy HS, Kim JS, Jeong YS, Jeong YT. Preparation of poly 2-hydroxyethyl methacrylate functionalized carbon nanotubes as novel biomaterial nanocomposites. Eur Polym J. 2008;44(3):579-586.

29. Wang L, Weng L, Song S, Zhang Z, Tian S, Ma R. Characterization of polyetheretherketone-hydroxyapatite nanocomposite materials. Mater Sci Eng A. 2011;528(10-11):3689-3696.

30. Ormsby R, McNally T, O’Hare P, Burke G, Mitchell C, Dunne N. Fatigue and biocompatibility properties of a poly(methyl methacrylate) bone cement with multi-walled carbon nanotubes. Acta Biomater. 2012;8(3):1201-1212.

31. Khang D, Kim SY, Liu-Snyder P, Palmore GT, Durbin SM, Webster TJ. Enhanced fibronectin adsorption on carbon nanotube/poly(carbonate) urethane: independent role of surface nano-roughness and associated surface energy. Biomaterials. 2007;28(32):4756-4768. 
32. Yang L, Zhang LJ, Webster TJ. Carbon nanostructures for orthopedic medical applications. Nanomedicine. 2011;6(7):1231-1244.

33. Stout DA, Basu B, Webster TJ. Poly(lactic-co-glycolic acid): carbon nanofiber composites for myocardial tissue engineering applications. Acta Biomater. 2011;7(8):3101-3112.

34. Tsang M, Chun YW, Im YM, Khang D, Webster TJ. Effects of increasing carbon nanofiber density in polyurethane composites for inhibiting bladder cancer cell functions. Tissue Eng Part A. 2011;17(13-14):1879-1889.

35. Mukhopadhyay K, Porwal D, Lal D, Ram K, Mathur GN. Synthesis of coiled/straight carbon nanofibers by catalytic chemical vapor deposition. Carbon. 2004:42(15):3254-3256.

36. Li X, Xu Z. Controllable synthesis of helical, straight, hollow and nitrogen-doped carbon nanofibers and their magnetic properties. Mater Res Bull. 2012;47(12):4383-4391.

37. Jian X, Jiang M, Zhou Z, et al. Gas-induced formation of Cu nanoparticle as catalyst for high-purity straight and helical carbon nanofibers. $A C S$ Nano. 2012;6(10):8611-8619.

38. Bertinetti L, Tampieri A, Landi E, et al. Surface structure, hydration, and cationic sites of nanohydroxyapatite: UHR-TEM, IR, and microgravimetric studies. J Phys Chem C. 2007;111(10):4027-4035.
39. Mark JE. Physical Properties of Polymer Handbook. New York: AIP; 1996.

40. Stojanović Z, Kačarević-Popović Z, Galović S, Miličević D, Suljovrujić E. Crystallinity changes and melting behavior of the uniaxially oriented iPP exposed to high doses of gamma radiation. Polym Degrad Stab. 2005;87(2):279-286.

41. Liu Y, Wang M. Fabrication and characteristics of hydroxyapatite reinforced polypropylene as a bone analogue material. J Appl Polym Sci. 2007;106(4):2780-2790.

42. Anselme K. Osteoblast adhesion on biomaterials. Biomaterials. 2000;21(7):667-681.

43. International Organization for Standardization. ISO 10993-5:2009: Biological evaluation of medical devices - part 5: tests for in vitro cytotoxicity. 2009.

44. International Organization for Standardization. ISO 10993-1:2009: Biological evaluation of medical devices - part 1: evaluation and testing within a risk management process. 2009.

45. Wörle-Knirsch JM, Pulskamp K, Krug HF. Oops they did it again! Carbon nanotubes hoax scientists in viability assays. Nano Lett. 2006;6(6):1261-1268.
International Journal of Nanomedicine

\section{Publish your work in this journal}

The International Journal of Nanomedicine is an international, peerreviewed journal focusing on the application of nanotechnology in diagnostics, therapeutics, and drug delivery systems throughout the biomedical field. This journal is indexed on PubMed Central, MedLine, CAS, SciSearch ${ }^{\circledR}$, Current Contents ${ }^{\circledR} /$ Clinical Medicine,

\section{Dovepress}

Journal Citation Reports/Science Edition, EMBase, Scopus and the Elsevier Bibliographic databases. The manuscript management system is completely online and includes a very quick and fair peer-review system, which is all easy to use. Visit http://www.dovepress.com/ testimonials.php to read real quotes from published authors. 